\title{
ENTRE A CURA E O ESPETÁCULO: a midiatização do discurso religioso na Nação dos $318^{1}$
}

\author{
Between the cure and the spectacle: mediatization of the religious \\ discourse in the Nation of the 318
}

\section{Carlos Renan Samuel Sanchotene}

Mestrando em Ciências da Comunicação pela Universidade do Vale do Rio dos Sinos (Unisinos) e bolsista CAPES na linha de pesquisa Midiatização e Processos Sociais, São Leopoldo, RS - Brasil, e-mail: carlos_sanchotene@yahoo.com.br

\begin{abstract}
Resumo
O presente artigo faz uma reflexão sobre o processo de midiatização do campo religioso e as estratégias de captura dos fiéis, a partir do programa televisivo religioso Hora dos Empresários, da Igreja Universal do Reino de Deus (IURD). Transmitido pela Rede Record de Televisão, o programa é destinado às pessoas que buscam uma solução para a crise financeira. Com estratégias distintas, os pastores oferecem ajuda aos telespectadores por meio dos serviços de autorreferencialidade, além da espetacularização do discurso religioso via imagens, testemunhos e dramatização. O estudo evidencia que a "cura" financeira, as conquistas e vitórias só podem ser alcançadas dentro do templo, através da Nação dos 318.
\end{abstract}

Palavras-chave: Midiatização. Religião. Espetacularização. Televisão.

\begin{abstract}
The present article makes a reflection about the process of mediatization of religious subject and the strategies of capturing churchgoers, based on religious televisive program Hora dos Empresários, from Igreja Universal do Reino de Deus (IURD). Broadcasted by Rede Record de Televisão, the program is directed from people who need a solution for financial crisis. With different strategies, pastors offer helps to television viewers from the service of self allusion, besides spectacularization of the religious discourse through images, testimonies and dramatization. This study shows that financial cure, conquest and victories only can be ranging inside the temple, from the Nação dos 318.
\end{abstract}

Keywords: Mediatization. Religion. Spectacularization. Television.

1 Este trabalho faz parte do projeto "Mídia e religião: um estudo dos novos dispositivos de contato entre o mundo da fé e o fiel", financiado pelo CNPq através do Edital Universal 2007 e coordenado pela professora Dra. Viviane Borell. 


\section{INTRODUÇÃO}

A problemática acerca das relações entre mídia e religião insere-se num quadro complexo em que os processos simbólicos engendrados por meio da televisão sinalizam uma atividade específica desenvolvida pelo campo religioso a partir de estratégias singulares de contato com os fiéis. Essas atividades demandam ofertas discursivas elaboradas através de processos de midiatização que garantam visibilidade ao campo religioso e, ao mesmo tempo, permanência junto aos fiéis.

Através de operações enunciativas, o dispositivo televisivo constrói um outro conceito de religião que não se concretiza mais só no âmbito institucional da Igreja, mas na esfera midiática. Nesse contexto e, em função da modernidade, os públicos encontram-se espalhados territorialmente e, através do funcionamento dos dispositivos midiáticos, a sociedade vive um momento caracterizado por novos modos de vivenciar, praticar e manifestar sua religiosidade.

A emergência neodevocional ${ }^{2}$ religiosa constrói novas comunidades midiáticas que se unem diante da tela da televisão, fazendo desse ambiente um espaço para buscar soluções de problemas familiares, de saúde, relacionamentos e financeiros. Do mesmo modo, essa nova comunidade que se forma surge de um momento em que a sociedade enfrenta mudanças de ordem cultural massiva para midiática, ou seja, a cultura midiática é caracterizada por um novo processo de interações sociais e estruturação de práticas sociais que são marcadas pela existência dos meios. As instituições religiosas criam laços com os telespectadores através de um discurso espetacularizado de contato com os fiéis.

Nesse sentido, o presente artigo busca discutir a transição da sociedade dos meios à sociedade midiatizada, bem como a questão da midiatização da religião e a espetacularização do discurso religioso, a partir de um caso específico, o programa Hora dos Empresários, da Igreja Universal do Reino de Deus (IURD), transmitido pela Rede Record de Televisão e destinado a pessoas que estão em dificuldades financeiras.

\section{DA SOCIEDADE DOS MEIOS À SOCIEDADE MIDIATIZADA}

A midiatização se encontra na existência de uma cultura, de lógicas e operações de natureza midiáticas que se inscrevem na vida da sociedade, permeando e constituindo as suas formas de organização e de funcionamento, definindo condições de acesso e de seu consumo, por parte dos indivíduos. Esse processo emerge na sociedade midiática e atualiza-se, de modo intenso e generalizado nos tempos em que vivemos, com a transformação daquela na "sociedade midiatizada".

Uma e outra evocam dois ambientes distintos e, consequentemente, ditam condições e parâmetros para a inserção e o funcionamento das mídias. De modo sucinto, na sociedade dos meios, os dispositivos estavam a serviço de determinadas funções que somente poderiam ser por eles realizadas em função das competências da sua própria natureza e das suas potencialidades enunciativas, com certa autonomia frente à existência dos demais campos sociais e ao seu trabalho de tematização pública (RODRIGUES, 1999).

A transformação da sociedade dos meios na sociedade midiatizada é uma consequência da interrupção do "contato direto" (LUHMANN, 2005) entre os indivíduos, pela presença das mídias. Intensifica-se a presença dos meios não apenas no âmbito do seu próprio território, mas também pelo processo de seu deslocamento e de sua expansão para outros campos. Suas operações são apropriadas como condições de produção para o funcionamento discursivo e simbólico de diferentes práticas sociais. Os meios já não podem ser mais entendidos como transportadores de sentidos, nem espaços de interação entre produtores e receptores, mas como marca, modelo, matriz, racionalidade produtora e organizadora de sentido (MATA, 1999).

O processo de midiatização, na concepção de Mata (1999), revela que há mudanças nos modos de pensar, nas matrizes e modelos culturais que reconfiguram as experiências identitárias, baseadas nas diversidades que os vínculos sociais constroem. $\mathrm{Na}$ contemporaneidade dos meios massivos, perpassados

\footnotetext{
2 Fenômeno que trata do surgimento de uma nova experiência religiosa. O neodevocional pode ser caracterizado pela falta de um modelo de representação através de antigas mediações, assim como a emergência técnica, gerando novas formas de interação e expressões religiosas.
} 
por interações complexas de produção e representação de sentidos, destacam-se as transformações nos regimes de visibilidade como o campo religioso, possibilitadas pelo campo das mídias, espaço de embates e legitimação dos campos.

$\mathrm{Na}$ sociedade dos meios, as mídias estão em uma 'zona de contato' com os demais campos sociais. Significa que os campos estão em interação, não conformados por suas fronteiras, enquanto territórios estáticos. Sendo sua atividade dominantemente de caráter simbólico, as práticas discursivas movemse instituindo processos e estratégias e disputas de sentido (RODRIGUES, 1999).

É a existência desses 'pontos de contatos' que vai desenvolver as possibilidades de interação entre os campos. No que se refere ao campo da mídia, esse é convertido numa espécie de 'ponto de acesso' ou pontos de conexão entre os indivíduos e os representantes dos sistemas abstratos, como define Giddens (1991) ao afirmar que as mídias, por meio de suas ações e dos seus "peritos", tratam de traduzir para os indivíduos conceitos e problemáticas que, parecendo distantes, necessitam do "trabalho mediador", como lugar que venha instituir elos de confiança e de segurança para os indivíduos. $\mathrm{Na}$ sociedade midiatizada, as mídias são convertidas em "sistema", que expande seu status e organiza as próprias operações, do que resulta a constituição de uma própria realidade.

Operando a partir dela, define, com base nas suas próprias condições, lógicas e operações, os processos de interação que vão estabelecer com o que é externo, definindo zonas de pregnância entre as suas fronteiras (internas) e aquilo que configura o espaço que lhe é exterior. De acordo com Fausto Neto (2007), a constituição da sociedade, as formas de vida e interações têm sido transformadas em função da convergência de fatores sociotecnológicos que foram disseminados na sociedade segundo lógicas de ofertas e de usos sociais.

A sociedade dos meios, portanto, coloca-se a serviço de uma organização de uma processualidade interacional com autonomia frente aos outros campos; já na sociedade midiatizada, o que predomina é a cultura midiática, convertida em referência sobre a qual a estrutura sócio-técnico-discursiva se estabelece, produzindo zonas de afetação em vários âmbitos da organização e da dinâmica da própria sociedade. Ou seja, se constituem como referência no modo de ser da própria sociedade.

\section{MIDIATIZAÇÃO DA RELIGIÃO}

Os campos midiático e religioso se constituem e interagem codeterminando relações entre campos sociais, caracterizados como instituições dotadas de legitimidade e certa autonomia com os demais campos. $\mathrm{Na}$ esfera do discurso religioso, o campo da mídia atua com caráter de superintendência, já que a partir de sua legitimidade garante visibilidade aos anseios dos demais campos.

A organização de estratégias midiáticas é fundamental para que a religião realize táticas de contato com seu público, o que decorre a partir do complexo fenômeno da midiatização constituído por um processo em que os dispositivos midiáticos agem sobre práticas sociais dos outros campos, como da religião, estruturando-as e engendrando-as por meio de operações tecnossimbólicas.

Os dispositivos tecnossimbólicos apreendem e capturam para si as gramáticas de outros campos e, através de um complexo processo de produção, constroem e estabelecem contratos de leitura. A comunicação midiática resulta da articulação entre dispositivos tecnológicos e as condições específicas de produção e recepção. Os dispositivos são os principais mecanismos de geração e de criação de novos símbolos para a religião. Segundo Verón (1997,p. 13), "um meio de comunicação social é um dispositivo tecnológico de produção-reprodução de mensagens associado a determinadas modalidades (ou práticas) de recepção de mensagens ditas". Como um suporte técnico, esse dispositivo engendra processos complexos e simbólicos de produção e recepção que configuram a estruturação do mercado discursivo.

Ainda de acordo com Verón (1997), a mídia ocupa um espaço central nas relações entre os campos sociais e os indivíduos. É ela quem promove conexões e por meio de suas operações acaba afetando os modos com que os campos e seus sujeitos relacionam-se. A centralidade da mídia representa que suas lógicas de funcionamento têm afetado os outros campos, havendo um cruzamento de interesses, negociações, disputas e inter-relações.

$\mathrm{Na}$ relação entre campos sociais, tomamse como partida algumas reflexões que discutem a atuação da mídia e seus vínculos frente a uma sociedade que está, cada vez mais, sofrendo interferências dos meios de comunicação. Gomes (2006) trabalha a midiatização no âmbito de um processo social complexo engendrado por mecanismos de produção 
de sentido social. Para o autor, "a midiatização é a reconfiguração de uma ecologia comunicacional" (GOMES, 2006, p. 121). Ou seja, através desse processo é possível compreender o funcionamento da mídia e da sociedade, que está cada vez mais se percebendo a partir do fenômeno midiático.

Como um canal de socialização, o autor afirma que a TV aproxima e integra as pessoas em uma comunidade nacional e universal. De acordo com ele, as interpretações do mundo, muitas vezes, são feitas a partir de pontos de referência que os indivíduos tomam sob o que é midiatizado pelos meios de comunicação de massa, surgindo assim uma nova ambiência, um novo modo de ser no mundo configurado pela presença da mídia.

Nesse mesmo sentido, Sodré (2006, p. 23) pensa o fenômeno como um novo bios, de qualificação cultural própria, a chamada tecnocultura, que "implica uma nova tecnologia perceptiva e mental, portanto, um novo tipo de relacionamento do indivíduo com as referências concretas e com a verdade [...]". É o que ele chama de escolha individualista, uma prática recorrente na sociedade moderna em relação a novos modos de pensar e agir, que parte dos desejos individuais, de qualificação existencial orientada pela mídia, a responsável pelos processos de interação social e construção social.

A evolução dos meios massivos complexifica os modos e estratégias utilizadas pelas mídias na captura e conquista de suas audiências. De acordo com Fausto Neto (2007), o que existe agora é um ambiente que funciona como uma nova forma de sociedade, nova forma de vida cujas interações sociais são atravessadas eimpulsionadas por ligações sociotécnicas. "A disseminação de novos protocolos técnicos em toda extensão da organização social, e de intensificação de processos que vão transformando tecnologias em meios de produção, circulação e recepção de discursos" (FAUSTO NETO, 2007, p. 92).

Através do atravessamento de dispositivos tecnossimbólicos, o movimento neopentecostal ${ }^{3}$, em especial a IURD, constrói sentidos religiosos inserindo sua programação religiosa nos lares dos crentes e não crentes, transformando o ambiente televisivo num espaço terapêutico, amenizando problemas e propondo soluções através da espetacularização do discurso religioso.

\section{A REDE RECORD E A IGREJA UNIVERSAL DO REINO DE DEUS (IURD)}

A Rede Record de Televisão foi fundada em 1953 pelo empresário Paulo Machado de Carvalho, tendo como principal concorrente, na época, a TV Tupi. Em 1972, 50\% de suas ações são vendidas para o comunicador Silvio Santos. A emissora entra na década de 80 com baixos indíces de audiência, operando em conjunto com a TVS, sendo praticamente uma retransmissora do SBT.

Em 1989, a emissora de Silvio Santos (sócio majoritário) e Paulo Machado de Carvalho (no momento havia se tornado o sócio minoritário) é vendida para a Igreja Universal do Reino de Deus, comandada pelo bispo Edir Macedo Bezerra. Em 1990, a Record apresentou seu novo slogan, "de volta pro futuro", ampliando sua programação, mantendo o jornalismo como carro-chefe e iniciando a formação de uma rede nacional de emissoras.

$\mathrm{Na}$ década de 90 , é desencadeada uma campanha contra a Rede Globo, que ataca a emissora do Bispo Macedo através dos telejornais. A situação piora quando a Globo coloca no ar a minissérie "Decadência", de Dias Gomes, que tinha como trama central a história de um pastor que criou uma seita para tirar dinheiro de pessoas humildes e ingênuas. Edir Macedo acreditou ser um ataque pessoal e declarou que nos próximos dez anos a Record seria a rede com maior potencial para ameaçar a emissora de Roberto Marinho.

$\mathrm{Na}$ mesma década começa a expansão da emissora paulista, que tem sua sede principal localizada em São Paulo, SP. Em 1995, a Record investiu pesado em equipamentos de última geração e mudou-se do bairro do Aeroporto para uma nova

\footnotetext{
3 Oriundo do pentecostalismo clássico e das igrejas cristãs tradicionais, pregam a prosperidade como meio de vida e curas milagrosas para enfermidades. Privilegiam o dualismo entre o mudo espiritual, dividindo-o entre Deus e o Diabo. Também adotam um sistema de relatos e testemunhos dos fiéis. No Brasil, as principais igrejas que os representam são: Igreja Universal do Reino de Deus, Igreja Internacional da Graça de Deus, Comunidade Evangélica Sara Nossa Terra, Igreja Evangélica Cristo Vive, Renascer em Cristo e Missão Cristã Pentecostal.
} 
instalação, na Barra Funda (atual sede). A partir daí, a emissora passou a contar com os equipamentos mais sofisticados da televisão brasileira. Com o apoio financeiro da Universal, a Record começou a comprar outras emissoras, expandindo ainda mais sua rede.

Atualmente, a emissora do Bispo Macedo opera em canal aberto e atinge 99,01 \% do território brasileiro, além da América do Sul, América do Norte, África, Europa e parte da Ásia. No Brasil, conta com 14 emissoras próprias, uma emissora própria internacional (TV Miramar de Moçambique) e 101 emissoras afiliadas. De acordo com dados do site da IURD, atualmente a igreja tem cerca de 8 milhões de fiéis somente no Brasil. Possui 9.600 pastores e gera 22 mil empregos diretos em mais de 4.700 templos instalados em 172 países.

Em 2008, teve um crescimento de 18\% na audiência em comparação com 2007 e um faturamento de US\$ 1 bilhão. Para 2009, a emissora pretende alcançar um faturamento $25 \%$ maior que no ano passado, chegando a um valor de $\mathrm{R} \$ 1,8$ bilhão. Parte dessa receita vem da Igreja Universal, que paga entre $\mathrm{R} \$ 300$ milhões e $\mathrm{R} \$ 400$ milhões pelo espaço que ocupa nas madrugadas. A programação da emissora, que tem como slogan "A caminho da liderança", investe em jornalismo, dramaturgia e entretenimento.

Em um total de 168 horas de programação da Record durante a semana, o espaço religioso ocupa 50 horas, o equivalente a $29,7 \%$ da programação semanal. A programação IURD não tem horários de programas definidos. A faixa horária do espaço comprado contém programas que vão ao ar em horários distintos durante a madrugada. Alguns programas são gravados, outros ao vivo. Entre eles, destacam-se: "Fala que eu te escuto", "Ponto de Luz", "Ponto de Fé", "SOS Espiritual" e "SOS".

\section{A HORA DOS EMPRESÁRIOS}

Oprograma da IURD éveiculado pela Rede Record em horários alternados durante a madrugada. Foi analisada uma edição do programa, que foi ao ar no dia 22 de junho de 2009, feito pela igreja de Porto Alegre (RS) e transmitido para todo o Estado do Rio Grande do Sul. Com duração de 30 minutos, a Hora dos Empresários é apresentado pelo pastor Milton César e pelo pastor José Ferraz.
O que distingue esse programa dos demais é o desejo de prosperar financeiramente, o que leva o fiel a percorrer um caminho imaginário da derrota ao sucesso. A Hora dos Empresários pode ser caracterizado como "tele-escuta", pois os telespectadores participam, deixam seus nomes e expõem seus problemas de ordem financeiros. Geralmente são microempresários que se encontram endividados ou perderam tudo. Também há pessoas que estão atrás de um emprego, mas não encontram. A solução é única: ir até um templo mais próximo, sempre na segundafeira, e participar do "Congresso Empresarial" que conta com a Nação dos 318.

$\mathrm{Na}$ Nação dos 318, um pastor lidera outros 318 que estão no altar frente aos fiéis, proferindo mensagens de salvação. Assim como nos tempos bíblicos, a Nação composta por 318 pastores estará nesta mesma batalha espiritual para que os fiéis possam resgatar sua autoestima, seu patrimônio, seu reconhecimento na sociedade, sua dignidade e sua prosperidade financeira e profissional.

Todas as sessões acontecem em horários diferenciados, que vão das $8 \mathrm{~h}$ da manhã até as 19h30. Os horários são pré-programados e acontecem em diversas cidades do Brasil. O telespectador é convidado a chegar um pouco mais cedo para receber uma "benção" especial, deixar seu nome para que os pastores coloquem-no no livro Nação dos 318 dos 7.000, para fazerem uma oração, bem como ouvirem os depoimentos de pessoas que "venceram" na vida. Nesse livro são colocados os nomes de 7.000 pessoas que se encontram em dificuldades financeiras.

\section{A ESPETACULARIZAÇÃO DO DISCURSO RELIGIOSOO NA NAÇÃO DOS 318}

Entre os ingredientes utilizados pelo programa Hora dos Empresários para tornar a mensagem religiosa mais atrativa estão ilustrações de histórias de vida e testemunhos emocionais permeados por elementos cinematográficos e novelescos, além da dramatização dos fatos, tornando assim mais verídico o que é apresentado.

A dramatização é um elemento utilizado não apenas pelo pastor, mas também ganha espaço quando é transmitida uma série de testemunhos ao público, dando ênfase aos problemas financeiros. 
Depoimento 1 (telefone) - "Eu estou desempregada e faz um ano que euperdi meu emprego. As contas vão aumentando e eu não estou conseguindo emprego. Eu estou dependendo da minha mãe e do meu filho pra sobreviver e pagar as contas. Já distribui uns 20 currículos, mas não estou conseguindo emprego, parece que tudo está dando errado na minha vida".

Pastor Milton César - "A senhora teria disposição pra estar conosco nesta segunda-feira? Eu vou comprar a sua briga e a senhora vai sair daqui com as portas abertas".

O pastor-apresentador ouve os telespectadores que entram ao vivo e oferece ajuda através de serviços de autorreferencialidade do próprio discurso religioso da IURD. No entanto, não basta apenas ouvir a palavra do pastor, é preciso participar das orações, ou seja, ir até a igreja presencialmente, onde está o "milagre". Ao telespectador são oferecidos diversos horários para que os mesmos procurem o templo, o que seria um primeiro passo para a salvação. Pelo telefone, os telespectadores expõem as suas situações, seus "dramas" e "desesperos", compondo a espetacularização do discurso da IURD.

O espetáculo, segundo Debord (1997), está se tornando uma mercadoria que tomou o espaço da vida social, fazendo com que o espectador crie vínculos com seu cotidiano. Para o autor, a vida das sociedades modernas torna-se uma imensa acumulação de espetáculos. Assim, o autor conceitua o espetáculo como "uma relação social entre pessoas, mediatizada por imagens" (DEBORD, 1997, p. 14).

A espetacularização cria uma relação de encantamento com o telespectador, e as dramatizações do programa iurdiano reforçam o caráter de veracidade dos fatos, dando ao telespectador uma legitimação do que está sendo transmitido. Por meio da espetacularização, os pastores-apresentadores atraem a atenção do telespectador, produzindo sentidos. A atuação e a performance do pastor, seja no palco (altar) ou no estúdio, é capaz de gerar vínculos e confiança na relação entre igreja e telespectador. A performance do apresentador materializa o espetáculo televisivo explorando as dificuldades da vida individual dos fiéis. Além disso, a imagem é o principal atrativo da espetacularização, capaz de fascinar o telespectador se adaptando às expectativas do imaginário social.

Através das mãos dos pastores sobre o livro Nação dos 318 dos 7.000, é feita uma oração em nome das pessoas que estão com seus nomes no livro. Esse gesto dá credibilidade ao discurso iurdiano, uma vez que o livro simboliza que para Deus não há limites e os problemas financeiros de cada credo são pequenos diante das grandezas de Deus e das maravilhas que Ele pode fazer.

Pastor Milton César - "Ó nosso Deus e nosso Pai, nós oramos pelas pessoas que estão com o nome aqui no livro dos 7.000, pessoas que estiveram conosco, nesta segunda-feira que passou, pessoas que enfrentaram a chuva, pessoas que não se curvaram e não vão se curvar, meu Deus, pessoas desempregadas, falidas, com o nome sujo, pessoas com causas na Justiça. Ó meu Deus, desamarre a vida dessas pessoas e dê a elas a vitória, $e$ em nome do Deus Pai, Filho e Espirito Santo, amém! Bem, 'tá' aqui, nós iremos seguir realizando várias oraçoes, durante o dia, a tarde, a noite e a madrugada".

Através desse ritual, o espetáculo é dimensionado pelo poder da imagem na sedução dos telespectadores. Esse poder da imagem sobre os espectadores, segundo Lipovetsky (2005, p. 3), "dirige o nosso mundo e o remodela de acordo com um processo sistemático de personalização cuja finalidade consiste essencialmente em multiplicar e diversificar a oferta". Dessa forma, o programa interage com o público através da sedução, do encantamento e do deslumbramento.

O programa é marcado por inserções de imagens, aparecendo cenas de pessoas angustiadas e desesperadas, além de uma trilha sonora que expressa uma sensação de terror. E no momento em que se começa a falar da Hora dos Empresários, a imagem, até então em preto e branco, agora passa a ter cor, com trilha sonora agradável, e as cenas de cultos se fazem presentes.

Além da sedução e do fascínio gerado pelas imagens, a espetacularização no programa telerreligioso abarca a dramatização dos fatos e a presença de depoimentos é fator in trínseco de legitimidade do discurso religioso - é o que mobiliza a sensibilidade do telespectador. No caso do programa iurdiano, os depoimentos servem como testemunho que, segundo Charaudeau (2007), instaura um imaginário da verdade verdadeira. Isso acontece quando pessoas comuns/anônimas são levadas da plateia ao altar da igreja para exporem suas intimidades, seus problemas, criando laços com os telespectadores que também enfrentam problemas semelhantes. 
Pastor - Qual é a boa notícia?

Depoimento 2 - Eu fir um voto pelo meu esposo, que estava desempregado bá 18 anos...

Pastor - Calma aí, o esposo da senhora estava desempregado há 18 anos?

Depoimento 2 - Isso, e dai eu fiz. um voto por ele e em uma semana chamaram ele nessa empresa e ele "tá" trabalhando já.

Pastor - Depois da oração dos 318 pastores, o marido da senhora, que estava desempregado há 18 anos, está trabalhando. As portas se abriram?

Depoimento 2 - Se abriram.

Pastor - Vai parar ou quer mais?

Depoimento 2 - Não, quero mais.

Pastor - Palmas pro nosso Deus, pessoal.

Para comprovar os "milagres" realizados por Deus através da Nação dos 318, uma demonstração é feita por meio do depoimento de fiéis. São filas de pessoas que se formam no altar do templo, por onde o pastor passa questionando a cada um qual sua atual situação financeira. Os depoimentos são uma forma de concretizar o discurso dos pastores e, ao mesmo tempo, criar vínculos com aqueles que estão presencialmente no templo ou que estão em casa.

Esses laços podem ser estabelecidos a partir do modo como a edição do programa é feita, do roteiro e da elaboração textual televisiva. Essas operações de sentidos criadas pelo programa televisivo, Tesch $(2005$, p. 1) as denomina como uma manipulação da mídia que "obedece a uma gramática do discurso midiático que precisa tornar-se cada vez mais familiar ao seu destinatário para ganhar legitimidade e interatividade. Através dessas práticas, ela se institucionaliza como espaço de mediação social". De acordo com o autor, nesse tipo de mediação, o que é do cotidiano e o que é comum acabam sendo uma processualidade de espetacularização.

É recorrente no fim de cada depoimento o pastor pedir aos fiéis que estão no culto uma salva de palmas para Deus e também reforçar que as conquistas só foram possíveis através da Nação dos 318. Sobre esse aspecto, é importante salientar as observações de Umberto Eco (1984) em relação ao aplauso no período da neotelevisão ${ }^{4}$. De acordo com o autor, os telespectadores que estão em casa ficam satisfeitos ao saberem que os aplausos não são fingidos. "Não lhe interessa se é ou não espontâneo, o que importa é que seja realmente televisivo" (ECO, 1984, p. 194). Após o pastor pedir os aplausos dos fiéis, a grua (que capta as imagens) sobrevoa o público acatando a solicitação feita.

Além disso, a interação e os vínculos constituídos entre os pastores e os telespectadores passam pela noção da confiança. Giddens (1991, p. 41) a define como "crença na credibilidade de uma pessoa ou sistema, tendo em vista um dado conjunto de resultados ou eventos, em que essa crença expressa uma fé na probidade ou amor de um outro, ou na correção de princípios abstratos (conhecimento técnico)".

A confiança é o principal valor presente no contrato entre o público telespectador e o pastor-apresentador, uma vez que aquele pede uma orientação, confiando que esse terá a solução para os seus problemas. Essa confiança é fundamental em relação ao que Giddens chama de "sistemas peritos", ou seja, "sistemas de excelência técnica ou competência profissional que organizam grandes áreas dos ambientes material e social em que vivemos hoje" (GIDDENS, 1991, p. 35).

A confiança em sistemas peritos é fortemente influenciada por experiências em pontos de acesso, caracterizados como "pontos de conexão entre indivíduos ou coletividades leigos e os representantes de sistemas abstratos [...], mas também junções nas quais a confiança pode ser mantida ou reforçada" (GIDDENS, 1991, p. 91). Nesse ponto, destaca-se o culto midiatizado, ou seja, o sistema funcionando em lógicas de midiatização que permite criar vínculos de confiança entre os telespectadores e os sistemas peritos.

No enredo telerreligioso, as pessoas são transformadas em protagonistas e espectadores do espetáculo que se estende à vida humana, pois as práticas sociais são tecidas nas relações interpessoais de cada pessoa/fiel. É o que acontece no programa da IURD, em que o comportamento do pastor diante da câmera cria a sensação de que ele se dirige ao fiel que está em casa e não ao público em geral.

\footnotetext{
${ }^{4}$ De acordo com Umberto Eco (1984), a neotelevisão aproxima-se da vida comum de cada um dos seus espectadores. Ela fala mais de si mesma e menos do mundo exterior. A produção e os bastidores passam a ser mostrados.
} 
No ambiente midiatizado, os sujeitos se tornam atores da encenação, buscando uma recriação imaginária da própria vida. $\mathrm{Na}$ novela da vida real, dramatizada pela TV, os personagens são compostos por todos os sujeitos, aquele que está na tela e aquele que está assistindo. No contexto da midiatização, há de se questionar a estratégia na enunciação dos pastores de que no templo ocorre a novela da vida real, uma vez que utilizam os mesmos dispositivos ficcionais para "transmitir o real".

Os sujeitos atorizados pelo programa acabam interpretando papéis que carregam todo o enredo da trama, o roteiro que sustenta as subversões que produzem identificações com o telespectador. Destacam-se nessa "trama" personagens como os empresários falidos e desempregados. Aqui, é importante salientar a opinião defendida por Charaudeau (2007) de que a sociedade também é corresponsável pelo espetáculo, já que as pessoas participam da produção que será mostrada na mídia, através dos mais diversos tipos de manifestação - nesse caso, quando vão à TV expor sua vida particular.

Segundo Eco (1984, p. 187), “aceita-se que freqüentemente o público manifeste identificações e projeções, vivendo na história representada as próprias pulsões e adotando como modelos os protagonistas dessa mesma história". É o que acontece com o público do programa, que projeta sua vida, suas dificuldades naqueles que estão do outro lado da tela.

Essa identificação se dá a partir de um senso de realidade estabelecido por bens simbólicos que, ao ser compartilhado, "o processo de socialização torna-se uma linha de experiência continua a partir da qual os espectadores definem o modo como vêem o mundo representado na mídia" (TESCH, 2005, p. 1). A "realidade" que se apresenta é, então, capaz de fazer com que o telespectador projete para si mesmo como exemplo daquilo que vive.

A Hora dos Empresários exerce sobre o público telespectador um trabalho de reconstrução, através dos diversos elementos que o compõem, apresentando uma realidade criada a favor da consolidação do discurso religioso, seja através dos pastores, produtores ou até mesmo pelos enquadramentos do dispositivo tecnológico televisivo. Os depoimentos mostrados pelo pastor são tão sólidos que se apresentam como uma realidade do fiel/telespectador, ou seja, as representações se consolidam a partir desses exemplos tanto em situações de midiatização quanto de interações face a face.

\section{CONSIDERAÇÕES FINAIS}

A midiatização da religião apresenta-se como um fenômeno não apenas do campo religioso, mas sim das práticas sociais, pois a sociedade contemporânea está cada vez mais se percebendo a partir dos processos midiáticos, ou seja, é um novo modo de ser no mundo. Dessa forma, a igreja se adapta às lógicas do funcionamento do campo midiático para atingir a população.

Em vista disso, observa-se o crescimento da IURD em meio a uma situação em que a população brasileira enfrenta dificuldades financeiras. Com o programa Hora dos Empresários, o discurso dos pastores consegue atingir e atrair a camada mais sofrida da sociedade: as pessoas com dívidas, os empresários falidos, os desempregados, etc. A estratégia de mostrar os relatos e depoimentos de pessoas que venceram na vida estimula qualquer indivíduo, não importa a religião, a superar as dificuldades e conquistar bens materiais.

O programa iurdiano é composto por estratégias que conferem aos telespectadores uma essência religiosa verdadeiramente espetacular, ou seja, privilegia-se mais a forma de apresentação do discurso do que o conteúdo efetivamente apresentado. Espetacularizar a partir das experiências individuais dos fiéis é a fórmula encontrada pelo programa para atrair a atenção do público.

Através do programa telerreligioso, as imagens possibilitam ao telespectador uma identificação com o outro e com um imaginário existente além do real vivido. $\mathrm{Na}$ atualidade, observa-se que o homem está cada vez mais isolado em vista do desenvolvimento tecnológico, e quando esse isolamento é rompido ele obtém reconhecimento social (mesmo que momentâneo através de lógicas de midiatização). E, um dos efeitos da midiatização é justamente a capacidade de cada um fazer sua própria edição do real, estabelecendo relações verdadeiras que são mantidas em situações de copresença com o dispositivo televisivo.

A Nação dos 318 é uma forte estratégia de contato, pois em nenhuma outra igreja o fiel vai encontrar tantas pessoas orando por ele-só no templo existem 318 pastores que formam uma sociedade 
da fé. A IURD também oferece diversos horários para o telespectador, portanto não há desculpas para não buscar a "cura".

O atual estágio fincanceiro de quem participa do Congresso é um fator que estimula o telespectador a bucar uma "solução" para sua crise. O discurso da IURD é de que a "cura" financeira só pode ser encontrada através da atitude de ir até o templo, pois cada ação produz uma reação, um resultado de prosperidade e riqueza.

Através do programa, os telespectadores compartilham da mesma situação e buscam uma solução que só pode ser resolvida no templo, pois é lá que está o segredo do sucesso financeiro. Nesse sentido, é fundamental a figura do pastor-apresentador na condução do programa, evocando passagens bíblicas e convocando os telespectadores "desesperados" a dirigirem-se à igreja.

\section{REFERÊNCIAS}

CHARAUDEAU, P. Discurso das mídias. São Paulo: Contexto, 2007.

DEBORD, G. A sociedade do espetáculo. Rio de Janeiro: Contraponto, 1997.

ECO, U. Tevê: a transparência perdida. In: ECO, U. (Org.). Viagem na irrealidade cotidiana. Rio de Janeiro: Nova Fronteira, 1984. p. 182-204.

FAUSTO NETO, A. Fragmentos de uma "analítica" da midiatização. Revista Matrizes, v. 1, p. 89-105, 2007. Disponível em: < http://www.revistas.univerciencia. org/index.php/MATRIZes/article/view/5236/5260>. Acesso em: 17 jun. 2009.

GIDDENS, A. As conseqüências da modernidade. São Paulo: UNESP, 1991.
GOMES, P. G. A Filosofia e a ética da comunicação na midiatização da sociedade. São Leopoldo: Unisinos, 2006.

LIPOVETSKY, G. A era do vazio: ensaios sobre o individualismo contemporâneo. São Paulo: Manole, 2005.

LUHMAN, N. A realidade dos meios de comunicação. São Paulo: Paulus, 2005.

MATA, M. C. De la cultura masiva a la cultura midiática. Diálogos de la Comunicación, n. 56, p. 80-91, 1999.

RODRIGUES, A. D. Experiência, modernidade e campo dos media. 1999. Disponível em: <http:// www.bocc.ubi.pt/pag/rodrigues-adriano-expcampmedia. pdf $>$. Acesso em: 12 jul. 2008.

SODRÉ, M. Eticidade, campo comunicacional e midiatização. In: MORAES, D. Sociedade midiatizada. Rio de Janeiro: Mauad, 2006. p. 19-31.

TESCH, A. Alguns apontamentos para compreender o midiático. São Leopoldo: PPGCC; Unisinos, 2005.

VERÓN, E. Esquema para el análisis de la mediatización. Revista Diálogos de la Comunicación, n. 48, p. 10-17, 1997.

Recebido: 10/07/2009

Received: 07/10/2009

Aprovado: 21/07/2009

Approved: 07/21/2009

Revisado: 08/01/2010

Approved: 01/08/2010 